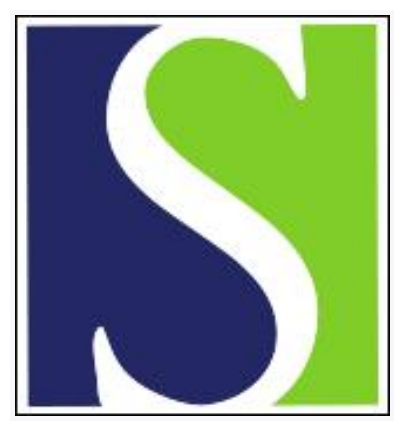

Scand J Work Environ Health 2002;28(2):109-116

https://doi.org/10.5271/sjweh.654

Issue date: Apr 2002

Effects of manual work on recovery from lateral epicondylitis

by Lewis M, Hay EM, Paterson SM, Croft P

Affiliation: Primary Care Sciences Research Centre, Keele University, Stoke-on-Trent, Staffordshire ST5 5BG, United Kingdom. a.m.lewis@cphc.keele.ac.uk

Refers to the following text of the Journal: 1995;21(6):478-486

Key terms: function recovery; general practice; lateral epicondylitis; longitudinal study; manual work; pain; prospective study; recovery; work

This article in PubMed: www.ncbi.nlm.nih.gov/pubmed/12019587 


\title{
Effects of manual work on recovery from lateral epicondylitis
}

\author{
by Martyn Lewis, PhD, ${ }^{1}$ Elaine M Hay, MD, ${ }^{1,2}$ Susan M Paterson, MA, ${ }^{1}$ Peter Croft, MD ${ }^{1}$
}

\begin{abstract}
Lewis M, Hay EM, Paterson SM, Croft P. Effects of manual work on recovery from lateral epicondylitis. Scand $J$ Work Environ Health 2002;28(2):109-116.
\end{abstract}

\begin{abstract}
Objectives This study investigates the influence of manual work on the persistence of lateral epicondylitis during a 12-month follow-up period after consultation in general practice.

Methods A cohort study was made of 164 adult consulters with tennis elbow, who had initially been recruited to a randomized controlled trial from 23 general practices in North Staffordshire and South Cheshire. As part of the recruitment process prior to treatment randomization, self-reported questionnaires on symptoms and sociodemographic characteristics were completed. Four weeks, six months, and twelve months later, the schedules were repeated. The main outcomes were measures of elbow symptoms (pain and function) based on a ten-point Likert scale. Total pain and function for the whole 12-month period were assessed using an area-under-the-curve (AUC) analysis. The pain and function scores were analyzed according to employment status (manual versus nonmanual work) and severe versus mild upper-limb stress in manual occupations.

Results The AUC scores for elbow pain and function were significantly higher for the manual workers, and manual work was associated with increased elbow pain and decreased function in the 4-week and 6-month follow-ups. The greater the severity of upper-limb stresses, the worse the outcome.

Conclusions Previous epidemiologic studies have shown that manual occupations are a risk factor for developing lateral epicondylitis. It is feasible that resuming manual work after treatment may hinder recovery or increase the risk of relapse. The study lends support to this hypothesis.
\end{abstract}

Key terms function recovery, general practice, longitudinal study, pain, prospective study, work.

Lateral epicondylitis (tennis elbow) is a painful condition with an estimated incidence of 4/1000 individuals affected annually (1). Its impact is determined by the extent of the disability that it causes, as well as the severity of the pain. Most cases are managed in primary care, and more than 40 possible treatments have been proposed (2), reflecting a lack of consensus about optimal management. In a recent randomized controlled trial in primary care, local corticosteroid injection was found to be more effective than naproxen for the early relief of lateral epicondylitis (3). The disorder does not usually persist for longer than 12 months, and $84 \%$ of the patients recruited into the trial were better at 12 months.

There are several risk factors for lateral epicondylitis, including age and gender (4-6). Evidence suggests that lateral epicondylitis can be mechanically induced (7), and it has been reported to be an occupational risk for workers exposed to significant upper-limb stress (811). For example, a study among gas and waterworks employees in Germany found that high exposure to strenuous work resulted in a 1.7-fold increase in the risk of developing the disorder (10).

One of the recommended early therapies for lateral epicondylitis is rest (12). Rest, involving absence from work, has social and economic implications as a prolonged therapy. A study in The Netherlands showed that $10-30 \%$ of all episodes of lateral epicondylitis resulted in absence from work, with an average duration of 12 weeks (13). By contrast, a progressive exercise program to improve muscular strength in the upper limb appears

1 Primary Care Sciences Research Centre, Keele University, Stoke-on-Trent, Staffordshire, United Kingdom.

2 Staffordshire Rheumatology Centre, The Haywood, Stoke-on-Trent, Staffordshire, United Kingdom.

Reprint requests to: Dr Martyn Lewis, Primary Care Sciences Research Centre, Keele University, Stoke-on-Trent, Staffordshire ST5 5BG, United Kingdom. [E-mail: a.m.lewis@cphc.keele.ac.uk] 
also to be effective therapy $(14,15)$. The dilemma of "rest or exercise" is relevant to the workplace, as little is known about the impact of continued work and type of work on recovery from tennis elbow.

Absence from work was uncommon in our cohort (3), and therefore it was implausible to carry out a detailed study of its effect on recovery. We did however have the opportunity to investigate whether manual work involving significant upper-limb tasks predicted the rate of recovery from lateral epicondylitis in primary care.

\section{Subjects and methods}

\section{Subjects and design}

This was a cohort study of 164 adults (aged 18-70 years) consulting a primary care physician about a new episode of lateral epicondylitis. They had initially been recruited into a pragmatic randomized controlled trial from 23 general practices in North Staffordshire and South Cheshire between November 1995 and December 1997 (3). Prior to commencement of the study, an investigators' meeting was held to discuss the trial protocol, including training of general practitioners when necessary and standardization of eligibility and treatment procedures. A "new episode" of lateral epicondylitis was defined as pain in the lateral region of the elbow, tenderness around the lateral epicondyle, elbow pain on resisted isometric contraction of the wrist extensors on formal examination, and no prior consultation concerning these symptoms in the same elbow during the preceding 12 months. Exclusion criteria were a history of inflammatory arthritis or gross structural abnormality of the elbow, contraindications to nonsteroidal antiinflammatories or local steroid injection, pregnancy or breastfeeding. The doctor based these inclusions and exclusions on the results of a clinical examination. In a standard baseline examination and interview, a research nurse also determined eligibility.

The patients had been randomized to receive one of the following three treatments: methylprednisolone $(20 \mathrm{mg})$ and lignocaine by local injection; naproxen $(500 \mathrm{mg})$ twice daily for 2 weeks, or placebo tablets for 2 weeks. The sample size of the cohort was pre-fixed according to the a priori requirements of the randomized controlled trial (3). Written informed consent was obtained, and the study was approved by the local research committees of North Staffordshire and South Cheshire.

\section{Questionnaires}

A questionnaire addressing the sociodemographic characteristics of the patient was administered by a research nurse at the time of recruitment, prior to treatment randomization. A pain manikin was used to assess co-morbidity, the degree of co-morbidity being determined by totaling the number of pain-identified regions of the manikin (a total of 15 regions coded). A baseline selfcompleted questionnaire was also carried out, which assessed tennis elbow symptoms including pain and disability. The questionnaires were repeated 4 weeks, 6 months, and 12 months later.

At each time interval, the occupational classification was determined in sequence. First, the question "At the moment, are you working full-time/part-time?" was used to determine whether subjects were employed or not. Secondly, the question "What is your main job?" determined the occupational task of workers. Employment status (manual or nonmanual work) was derived using the classification of the Office of National Statistics (16).

The classification of "manual" and "nonmanual" work used by the Office of National Statistics is not independent of social status. To study outcome in relation to upper-limb tasks independently of social class, a separate review was carried out whereby manual workers were classified into "severe" or "mild" exposure to upper-limb stress by occupational experts at the Environmental Epidemiology Unit of the Medical Research Council at Southampton, the United Kingdom. To protect against possible information bias, the reviewers were kept blind to the outcome measurements of the study. They also subcategorized "severe" upper-limb stress into forearm and upper-arm stress to assess their separate impacts; these categories were not mutually exclusive. For example, in North Staffordshire several women worked in the pottery industry, and therefore jobs such as "cup sponger" and "pottery filler" appeared and were coded as manual, with "severe" forearm stress; examples of manual jobs with "severe" upper arm stress are tire and exhaust fitters and truck drivers. Examples of manual jobs with "mild" upper-limb stress include barmen and hairdressers.

\section{Primary outcomes}

Primary outcomes for the study were self-completed measures of elbow symptoms including pain and function. These symptoms were measured on a 10-point Likert scale (scores: 0-9). Pain severity was addressed with the use of the following request: "Indicate the worst elbow pain you have had over the past 24 hours", with 0 representing "no pain" and 9 indicating "pain as bad as it can be". Function was assessed by "Thinking back over the past 24 hours, ... describe how your tennis elbow has affected what you have been able to do", with a score of 0 representing "able to do everything" and 9 indicating "unable to do anything". Assessment was 
performed on the following four separate occasions: at the baseline assessment, after 4 weeks, after 6 months and after 12 months.

Serial assessment enabled us to perform an area-under-the-curve (AUC) analysis (17) for each symptom, to obtain scores that summarized total 12-month experience for both elbow pain and function separately.

\section{Secondary outcomes}

Secondary outcomes could be divided according to the baseline and follow-up assessments as follows: (i) baseline assessment: patients' subjective opinion about tennis elbow causation; (ii) follow-up assessment: use of painkillers in the 48 hours prior to the interview, time off work, general practitioner consultation for elbow complaints subsequent to treatment randomization (data was collated by reviewing the patients' medical records, both computerized and hardcopy).

\section{Clinical interpretation}

At each assessment, pain and function scores were summed to form an overall elbow symptom score (scale: 0-18). Overall scores at each follow-up were compared with the baseline overall score, and a relative improvement in excess of $30 \%$ (preassigned prior to analysis) was considered to represent "clinically significant improvement" in elbow symptoms.

\section{Baseline characteristics of the study groups}

In table 1 we show the sociodemographic and clinical characteristics of the manual and nonmanual groups at the time of the baseline assessment. There was little difference between the two groups with respect to gender, duration of pain, and co-morbidity, but the manual group was younger and had more severe symptoms. By chance, proportionally more of the manual group, compared with those in the nonmanual group, were randomized to receive an injection in contrast to being given naproxen tablets.

\section{Statistical analysis}

The pain and function scores were summarized using mean scores with $95 \%$ confidence intervals (95\% CI). The sample size of the study was sufficiently large to enable us to carry out a parametric statistical analysis on the data. The pain and function outcome variables were numerical measures; hence multiple linear regression analyses were used to derive estimates of the mean differences in scores between the groups, after adjustment for age, gender, treatment, co-morbidity, duration of pain, and baseline symptom score. In addition, logis- tic regression analyses were used to compare the likelihood (odds ratio) of "clinical improvement" between groups after multivariate adjustment. Logistic regression analysis was also used to assess the impact of manual versus nonmanual work on secondary outcomes (work causation, time off work, re-consultation and use of painkillers), after adjustment for age, gender, treatment, co-morbidity, duration of pain, and baseline symptom score. All statistical testing was two-tailed with a significance level of $5 \%$. The analyses were carried out using SPSS version 10.0 (18).

\section{Results}

\section{Response}

All 164 patients recruited into the study were successfully followed by the research nurse. The number of patients self-completing all elbow pain assessments was $146(89 \%)$, and $147(90 \%)$ completed the elbow function assessments. These were the numbers included for deriving AUC total scores for pain and function, respectively.

Table 1. Characteristics of the manual and nonmanual groups in the baseline assessment. ${ }^{\mathrm{a}}$

\begin{tabular}{|c|c|c|c|c|}
\hline \multirow[t]{2}{*}{ Risk factors } & \multicolumn{2}{|c|}{$\begin{array}{l}\text { Manual } \\
(\mathrm{N}=72)\end{array}$} & \multicolumn{2}{|c|}{$\begin{array}{l}\text { Nonmanual } \\
(\mathrm{N}=52)\end{array}$} \\
\hline & $\mathrm{N}$ & $\%$ & $\mathrm{~N}$ & $\%$ \\
\hline \multicolumn{5}{|l|}{ Age } \\
\hline$<50$ years & 53 & 74 & 33 & 64 \\
\hline$\geq 50$ years & 19 & 26 & 19 & 36 \\
\hline \multicolumn{5}{|l|}{ Gender } \\
\hline Female & 32 & 44 & 26 & 50 \\
\hline Male & 40 & 56 & 26 & 50 \\
\hline \multicolumn{5}{|l|}{ Duration of pain } \\
\hline$\leq 3$ months & 52 & 72 & 35 & 67 \\
\hline$>3$ months & 20 & 28 & 17 & 33 \\
\hline \multicolumn{5}{|l|}{ Co-morbidity ${ }^{b}$} \\
\hline Low & 36 & 50 & 26 & 50 \\
\hline High & 36 & 50 & 26 & 50 \\
\hline \multicolumn{5}{|c|}{ Baseline symptom severity c } \\
\hline Low & 33 & 47 & 32 & 61 \\
\hline High & 37 & 53 & 20 & 39 \\
\hline \multicolumn{5}{|l|}{ Treatment } \\
\hline Injection & 26 & 36 & 12 & 23 \\
\hline Naproxen & 19 & 26 & 19 & 37 \\
\hline Placebo & 27 & 38 & 21 & 40 \\
\hline
\end{tabular}

${ }^{a}$ None of the comparisons were statistically different at the $5 \%$ significance level.

b Low co-morbidity signifies fewer than three areas of pain according to a body manikin with 15 defined regions.

c Low baseline symptom score refers to a total score (baseline pain score + baseline function score) of 8 or less (where 8 was the median total score). 


\section{General findings}

For the respondents to the elbow pain assessment, the mean scores at each follow-up interval were as follows: 5.1 (95\% CI 4.7-5.4) in the baseline examination, 3.2 (95\% CI 2.8-3.6) at 4 weeks; 2.1 (95\% CI 1.8-2.5) at 6 months, 1.5 (95\% CI 1.1-1.8) at 12 months. Similarly, for the respondents to the elbow function assessment, the mean scores at each follow-up interval were 3.6 (95\% CI 3.2-3.9) in the baseline examination, $2.3(95 \%$ CI 1.9-2.6) at 4 weeks, $1.6(95 \%$ CI 1.3-1.9) at 6 months; 0.9 (95\% CI 0.7-1.2) at 12 months. These results equated to AUC totals with mean scores of 27.6 (95\% CI 24.3-30.8) and 19.2 (95\% CI 16.2-22.1) for pain and function, respectively.

\section{Nonphysical risk factors}

Female gender, younger age, short illness duration, and co-morbidity were linked, but not significantly $(\mathrm{P}>0.05)$,

Table 2. Scores for the area under the curve for elbow pain and function, stratified by nonphysical risk factors.

\begin{tabular}{|c|c|c|c|c|}
\hline \multirow[t]{2}{*}{ Risk factors } & \multicolumn{2}{|r|}{ Pain } & \multicolumn{2}{|c|}{ Function } \\
\hline & Mean & $95 \% \mathrm{Cl}$ & Mean & $95 \% \mathrm{Cl}$ \\
\hline \multicolumn{5}{|l|}{ Age } \\
\hline$<50$ years & 28.4 & $24.3-32.5$ & 19.5 & $15.6-23.4$ \\
\hline$\geq 50$ years & 26.1 & $20.6-31.6$ & 18.5 & $13.7-23.3$ \\
\hline \multicolumn{5}{|l|}{ Gender } \\
\hline Female & 28.4 & $23.6-33.1$ & 20.2 & $15.8-24.5$ \\
\hline Male & 26.8 & $22.2-31.3$ & 18.2 & $14.1-22.4$ \\
\hline \multicolumn{5}{|c|}{ Duration of pain } \\
\hline$\leq 3$ months & 28.2 & $24.3-32.1$ & 19.8 & $16.1-23.4$ \\
\hline$>3$ months & 26.0 & $20.1-31.9$ & 17.7 & $12.5-23.0$ \\
\hline \multicolumn{5}{|l|}{ Co-morbidity a } \\
\hline Low & 25.9 & $21.0-30.7$ & 16.4 & $12.3-20.6$ \\
\hline High & 29.2 & $24.8-33.6$ & 21.9 & $17.6-26.2$ \\
\hline \multicolumn{5}{|c|}{ Baseline symptom severity b } \\
\hline Low & 24.0 & $19.6-28.4^{c}$ & 14.8 & $11.2-18.4^{c}$ \\
\hline High & 31.2 & $26.4-36.0$ & 24.0 & $19.3-28.7$ \\
\hline
\end{tabular}

a Low co-morbidity signifies fewer than three areas of pain according to a body manikin with 15 defined regions.

b Low baseline symptom score refers to a total score (baseline pain score + baseline function score) of 8 or less (where 8 was the median total score)

c $\mathrm{P}<0.05$ by t-test for the comparison of the stratified groups of nonphysical risk factors.

Table 3. Patients attributing onset of tennis elbow to work in the baseline assessment.

\begin{tabular}{lrrrrr}
\hline \multirow{2}{*}{ Group } & \multicolumn{4}{c}{ Work causation } \\
\cline { 2 - 3 } & \multicolumn{2}{c}{ Yes } & & \multicolumn{2}{c}{ No } \\
\cline { 2 - 3 } \cline { 2 - 5 } & N & $\%$ & & $N$ & $\%$ \\
\hline All patients & 25 & 15 & 139 & 85 \\
All workers & 23 & 19 & 101 & 81 \\
$\quad$ Manual & 18 & 25 & & 54 & 75 \\
Nonmanual & 5 & 10 & & 47 & 90 \\
\hline
\end{tabular}

with increased AUC scores for pain and function (table 2). As may be expected, baseline symptom severity was strongly associated with elbow pain and function during the follow-up, as measured by the AUC scores.

\section{Employment details}

The number of employed patients was $124(76 \%)$ at the time of the baseline examination, $126(77 \%)$ in the 4week follow-up, $129(79 \%)$ in the 6-month follow-up, and 122 (74\%) in the 12-month follow-up. There were few changes in the subjects' job descriptions during the 12 months of follow-up.

Of the 164 patients recruited for the baseline examination, $25(15 \%)$ attributed their condition to work [23 (19\%) of current workers], $12(7 \%)$ to sport, and 18 (11\%) to a previous injury to the elbow. These categories may not be mutually exclusive, however. A belief that work had induced the condition was significantly higher among the baseline manual workers than those doing nonmanual work (OR 3.0, 95\% CI 1.0-9.6 after adjustment for age, gender, treatment, co-morbidity, duration of pain, and baseline symptom score) (table 3 ).

\section{Physical risk factors (manual versus nonmanual work)}

The AUC scores for elbow pain were significantly higher for the manual workers $(\mathrm{P}<0.05)$. When the individual time points of follow-up were analyzed, a significant difference in elbow pain was evident between the manual and nonmanual workers at the time of the 6month follow-up, after multivariate adjustment (table 4), the average unstandardized pain score being 2.7 for the manual group and 1.4 for the nonmanual group. Similarly, with respect to elbow function, the adjusted AUC scores were significantly higher for the manual workers $(\mathrm{P}<0.05)$, and significant differences in function between the manual and nonmanual groups were evident in both the 4-week and 6-month follow-ups (table 4). In the 6-month follow-up, the average unstandardized function score was 1.8 for the manual group and 1.0 for the nonmanual group. The adjusted mean differences in the AUC pain score between the manual and nonmanual groups were as follows: 10.0 (function score 6.8) for all persons receiving treatment, 8.8 (function score 0.1 ) for those given an injection, 12.3 (function score 9.6) for those given naproxen, 5.0 (function score 5.8) for those given placebo.

"Clinical improvement" was significantly greater among the nonmanual workers than among the manual workers at both the 4-week and 6-month follow-ups, after multivariate adjustment. In comparison with manual workers, there were $23 \%$ more nonmanual workers with "improved" elbow symptoms by the time of the 6month follow-up (table 5). 
Differences, though statistically nonsignificant $(P>0.05)$, were also evident between the manual and nonmanual workers in relation to secondary indicators of elbow problems, such as time off work, reconsultation, and use of painkillers. Seventeen persons (14\%) had taken time off paid employment due to their elbow symptoms by 4 weeks: 13 (18\%) manual workers and 4 (8\%) nonmanual workers (OR 2.4, 95\% CI 0.7-8.5, after adjustment for age, gender, treatment, co-morbidity, duration of pain, and baseline symptom score). The median number of days taken off was 7.0 for the manual group and 3.5 for the nonmanual group. By the time of the 12-month assessment, two additional patients had taken time off because of their elbow symptoms, and they belonged to the manual group. The number of patients who had further consulted their general practitioner regarding elbow problems was $19(28 \%)$ for the manual workers and $9(18 \%)$ for the nonmanual workers by the time of the 4-week follow-up (adjusted OR 2.1, 95\% CI 0.8-5.6), extending to $31(45 \%)$ and 20 (38\%), respectively, in the 6-month follow-up. Use of painkillers was higher in the manual group; for example, 35 (48\%) manual workers but only 20 (38\%) nonmanual workers were taking painkillers at the time of the 4-week follow-up assessment (OR 1.6, 95\% CI 0.7-3.4).

\section{Variations in upper-limb stress}

Manual workers exposed to "severe", compared with "mild", upper-limb stress (labeled in the baseline examination) had higher adjusted mean AUC scores for pain (mean AUC 6.9, 95\% CI -5.8-19.5) and function (mean AUC 5.7, 95\% CI -5.9-17.3). In terms of "clinical improvement", the manual workers exposed to "mild" stress were more likely to have improved by the time of the 4-week, 6-month, and 12-month assessments (table 5 ); these differences were not statistically significant owing to the small numbers after the stratification of employment status into manual and nonmanual groups.

Among the manual workers exposed to "severe" upper-limb stress, improvement was a little better for those subjected to upper-arm stress than for those subjected to forearm stress. In the 4-week follow-up, 8 (35\%) persons exposed to forearm stress at work and 13 (46\%) exposed to upper-arm stress showed "clinical improvement" with respect to elbow symptoms. By the time of the 6-month follow-up, 12 (52\%) persons had improved following exposure to forearm stress at work compared with $17(59 \%)$ of those exposed to upper-arm stress. None of these differences were statistically significant.

Computer workers are subjected to forearm stress due to repetitive movements of the muscles required for typing. The mean adjusted AUC scores for both pain and function were higher for the occupational groups exposed to considerable computer work [ie, clerical workers and secretaries (mean pain score of 22.4 and mean function score of 17.1)] than in the other nonmanual work groups (mean pain score of 21.4 and mean function score of 13.8); these differences were not statistically significant.

Table 4. Pain and function scores of the employed adults, stratified by work status (manual or nonmanual work). (95\% Cl $=$ confidence interval, $\mathrm{AUC}=$ area under the curve)

\begin{tabular}{|c|c|c|c|c|c|c|}
\hline \multirow[t]{3}{*}{ Symptom } & \multicolumn{4}{|c|}{ Employment status a } & \multirow{2}{*}{\multicolumn{2}{|c|}{$\begin{array}{l}\text { Absolute } \\
\text { difference }{ }^{b}\end{array}$}} \\
\hline & \multicolumn{2}{|c|}{ Manual } & \multicolumn{2}{|c|}{ Nonmanual } & & \\
\hline & Mean & $95 \% \mathrm{Cl}$ & Mean & $95 \% \mathrm{Cl}$ & Mean & $95 \% \mathrm{Cl}$ \\
\hline \multicolumn{7}{|l|}{ Pain } \\
\hline $\begin{array}{l}\text { Baseline } \\
\text { At } 4 \text { weeks } \\
\text { At } 6 \text { months } \\
\text { At } 12 \text { months }\end{array}$ & $\begin{array}{l}5.5 \\
3.5 \\
2.7 \\
\text { S } 1.6\end{array}$ & $\begin{array}{l}5.0-6.0 \\
2.9-4.2 \\
2.1-3.3 \\
1.0-2.1\end{array}$ & $\begin{array}{l}4.6 \\
3.0 \\
1.4 \\
1.4\end{array}$ & $\begin{array}{l}4.1-5.2 \\
2.3-3.7 \\
1.0-1.9 \\
0.8-2.0\end{array}$ & $\begin{array}{l}0.8 \\
0.7 \\
1.1 \\
0.1\end{array}$ & $\begin{array}{r}0.0-1.6 \\
-0.1-1.6 \\
0.2-1.9 \\
-0.7-0.9\end{array}$ \\
\hline Total c & 33.0 & $27.4-38.6$ & 21.6 & $17.7-25.5$ & 10.0 & $2.7-17.3$ \\
\hline \multicolumn{7}{|l|}{ Function } \\
\hline $\begin{array}{l}\text { Baseline } \\
\text { At } 4 \text { weeks } \\
\text { At } 6 \text { months } \\
\text { At } 12 \text { months }\end{array}$ & $\begin{array}{l}3.7 \\
2.7 \\
1.8 \\
\text { S } 1.0\end{array}$ & $\begin{array}{l}3.1-4.2 \\
2.1-3.2 \\
1.3-2.4 \\
0.6-1.4\end{array}$ & $\begin{array}{l}3.3 \\
1.9 \\
1.0 \\
0.7\end{array}$ & $\begin{array}{l}2.7-3.8 \\
1.3-2.4 \\
0.6-1.5 \\
0.4-1.1\end{array}$ & $\begin{array}{l}0.4 \\
0.8 \\
0.7 \\
0.2\end{array}$ & $\begin{array}{r}-0.4-1.2 \\
0.1-1.6 \\
0.0-1.4 \\
-0.4-0.8\end{array}$ \\
\hline Total c & 22.4 & $17.1-27.7$ & 14.4 & $10.8-18.0$ & 6.8 & $0.3-13.3$ \\
\hline
\end{tabular}

a Employment status specifies the manual or nonmanual grouping of the employed persons according to their current occupation at the time of the patient interview. Categorization for AUC analysis was based on occupation at baseline.

${ }^{b}$ Absolute difference is the estimated mean difference in the scores (manual group - nonmanual group) adjusted for age, gender, duration of pain, co-morbidity, baseline pain and function scores (except at the baseline assessment), and treatment.

${ }^{c}$ AUC analysis.

Table 5. Clinical interpretation of the Likert scores for elbow symptoms, showing the number and percentage of patients with "clinical improvement" (> 30\% relative improvement compared with baseline) at follow-up.

\begin{tabular}{|c|c|c|c|c|c|c|c|c|c|c|}
\hline \multirow[t]{3}{*}{ Follow-up } & \multicolumn{5}{|c|}{ Employment status (workers) } & \multicolumn{5}{|c|}{ Upper-limb stress (manual workers) } \\
\hline & \multicolumn{2}{|c|}{ Nonmanual } & \multicolumn{2}{|c|}{ Manual } & \multirow{2}{*}{$\frac{\text { Difference }}{(\%)}$} & \multicolumn{2}{|c|}{ Mild } & \multicolumn{2}{|c|}{ Severe } & \multirow{2}{*}{$\frac{\text { Difference }}{(\%)}$} \\
\hline & $\mathrm{N}$ & $\%$ & $\mathrm{~N}$ & $\%$ & & $\mathrm{~N}$ & $\%$ & $\mathrm{~N}$ & $\%$ & \\
\hline 4 weeks & 28 & 55 & 33 & 50 & $5^{a}$ & 17 & 53 & 16 & 47 & 6 \\
\hline 6 months & 47 & 86 & 41 & 63 & $23^{a}$ & 21 & 68 & 20 & 59 & 9 \\
\hline 12 months & 42 & 82 & 53 & 84 & -2 & 27 & 87 & 26 & 81 & 6 \\
\hline
\end{tabular}

a $\mathrm{P}<0.05$ by logistic regression adjusting for age, gender, duration of pain, co-morbidity, baseline symptom scores, and treatment. 


\section{Discussion}

In this prospective cohort study we have shown that manual work predicted a slower recovery from lateral epicondylitis among patients followed for 12 months after their initial consultation with a general practitioner. This association was still evident after adjustment for other factors predictive of outcome, including social status. In addition, manual workers were more likely than nonmanual workers to have time off work, consult with their general practitioner, and use painkillers.

Our question addressing the patients' subjective opinions about the cause of their tennis elbow suggests that sport and occupation are among the factors that are perceived to be linked with the onset of the condition, as indeed the epidemiologic literature suggests (8-11, 19-22). In our study, $7 \%$ of the participants thought that their elbow problem was a direct result of playing sport, and $19 \%$ of the workers attributed their condition directly to their occupation in their baseline assessment.

In the 6-month follow-up there were $23 \%$ more patients with "clinical improvement" in the nonmanual group than in the manual group, a significant difference that, by 12 months, had disappeared. This difference in recovery rate between the manual and nonmanual workers may be explained by two independent factors: workrelated exposure to stress of the upper-limb and factors other than the physical stress of work related to social class. Within the manual work group, patients exposed to "severe" upper-limb stress were less likely to recover than those exposed to "mild" stress during all the follow-up intervals, although the sample size was small and the differences were not statistically significant. These findings tend to suggest that upper-limb tasks predict slower recovery from acute tennis elbow symptoms independently of social status. The association was stronger for jobs involving forearm stress than for those with upper-arm stress; this finding further supports the interpretation that recovery is task-related.

It may not be surprising that exposure to continued manual work would hinder recovery in light of the evidence that manual work is a risk factor for the onset of epicondylitis. However, most of the subjects (approximately $80 \%$ ) were "clinically improved" with respect to elbow symptoms after 12 months of follow-up, independent of the type of work and social activity. This similarity of results between groups after 12 months seems to imply that there is no prospect of permanent damage if patients are returned to manual work - only excess suffering on the part of the person so returned.

Along with social class and upper-limb stress, severity of pain in the initial consultation with the general practitioner was the other main risk factor for slowed recovery from lateral epicondylitis. This finding agrees with those of Gerberich et al (5), who showed that the degree of pain prior to treatment was a significant predictor of complete recovery. These authors also listed female gender as being significantly predictive of a higher chance of nonrecovery. Although not statistically significant, female gender was also associated with a worse prognosis in our study.

The manual workers averaged more severe pain and disability in the baseline assessment, and, by chance, they were more likely to have been randomized to receive a corticosteroid injection as their trial treatment. An increased severity of pain was associated with a worse prognosis, but injection was indicative of a better prognosis. The internal validity of the main investigation was strengthened by using a multivariate statistical analysis to control for these potential confounders. It enabled us to estimate effect differences between the manual and nonmanual groups while controlling for imbalances between the groups in relation to other important baseline characteristics, such as treatment and baseline severity of pain. Interaction with treatment was not statistically significant, although differential recovery between the manual and nonmanual groups was more marked among those treated with naproxen.

There were few changes in occupation across the follow-up period. It is possible that patients remain in their occupations but, in an effort to counteract pain and discomfort in the elbow, alter the level of exposure to tasks that could cause stress to the upper-limb (eg, work for shorter hours, lower tempo, or less load or change of tasks or work techniques). We did not assess all these changes in occupational tasks, but it is unlikely that the nonmanual workers would have changed their work practices more than the manual workers. Indeed, in our study, the manual workers were the ones most likely to have taken time off work.

Computer work is known to be associated with increased musculoskeletal problems (23-25). Computer work is classified as nonmanual. Clerical workers and secretaries are common users of computers. Both pain and function were higher in these occupational groups than in the other nonmanual work groups, and this finding supports our conclusion that forearm stress may delay recovery.

The primary outcome variables of our study (pain and function scales) were limited to the past 24 hours, and they may be sensitive to fluctuations in daily workload. However, our results for the secondary outcome measures of time off work and subsequent consultation with a general practitioner for elbow problems, based on longer intervals of assessment, also indicate that manual work delays recovery.

The classification of manual work-related upperlimb stress was performed blind to outcome and therefore avoided possible bias in the recording of "mild" and "severe" groups. The research nurse was not blind to 
social and occupational status, but, as this study was secondary to the randomized controlled trial of local corticosteroid injection and naproxen (3), it is unlikely that she would consciously have biased the results in a way that would have affected this investigation. In addition, the primary outcomes of pain and function were based on self-reports.

Only 19 patients had taken time off work because of their elbow complaints during the 12-month followup period. Patients presumably take time off in an effort to relieve their symptoms, and they may be expected to have a better outcome than those who do not take time off. In support of this assumption, patients who took time off work, compared with those who continued to work during 12 months of follow-up, had lower mean adjusted AUC scores for pain (AUC score 15.4, 95\% CI 5.2-25.5) and function (AUC score 15.5, 95\% CI 6.2-24.8). If patients' symptoms are eased by taking time off work, the fact that we still observed higher pain and disability scores for the manual group who had more time off suggests that our estimates of the difference in effect between manual and nonmanual workers is conservative.

The study population was characteristic of patients who seek help from a general practitioner because of lateral epicondylitis fulfilling our selection criteria. We tested the generalizability of the study population for possible selection bias by examining whether patient characteristics pertaining to high recruiting general practitioners differed from those of low recruiting general practitioners (3). Eleven of the 37 general practitioners recruited six or more patients, accounting for 94 (57\%) of the 164 in the study population, and the baseline patient characteristics and allocation of treatment interventions were similar with respect to high and low recruiting practices.

In conclusion, manual work was a significant marker of slower recovery from acute lateral epicondylitis. Previous epidemiologic studies have shown that manual occupations are a risk factor for the development of lateral epicondylitis. We have extended these findings to show that they are also related to recovery from the condition. It is feasible that resuming manual work after treatment, particularly in association with forearm stress, may hinder recovery or increase the risk of relapse. This possibility needs investigating in future studies.

\section{Acknowledgments}

We thank the general practitioners from the North Staffordshire and South Cheshire Community Musculoskeletal Research Group for their enthusiasm and help, Gill
Latham for providing holiday cover for the study nurse, and Brian Pannett and Keith Palmer of the Environmental Epidemiology Unit of the Medical Research Council, Southampton University, for their work in coding the upper-limb tasks.

We are grateful to the Arthritis Research Campaign, the United Kingdom, for funding this study.

\section{References}

1. Hamilton PG. The prevalence of humeral epicondylitis: a survey in general practice. JR Coll Gen Pract 1986;36:464-5.

2. Chard MD, Hazleman BL. Tennis elbow - a reappraisal. Br J Rheumatol 1989;28:186-90.

3. Hay EM, Paterson SM, Lewis M, Hosie G, Croft P. Pragmatic randomised controlled trial of local corticosteroid injection and naproxen for treatment of lateral epicondylitis of elbow in primary care. BMJ 1999;319:964-8.

4. Allander E. Prevalence, incidence, and remission rates of some common rheumatic diseases or syndromes. Scand J Rheumatol 1974;3:145-53.

5. Gerberich SG, Priest JD. Treatment for lateral epicondylitis: variables related to recovery. Br J Sports Med 1985;19 (4):224-7.

6. Verhaar JA. Tennis elbow: anatomical, epidemiological and therapeutic aspects. Int Orthop 1994;18(5):263-7.

7. Briggs CA, Elliott BG. Lateral epicondylitis: a review of structures associated with tennis elbow. Anat Clin 1985;7 (3): 149-53.

8. Kurppa K, Viikari-Juntura E, Kuosma E, Huuskonen M, Kivi $\mathrm{P}$. Incidence of tenosynovitis or peritendinitis and epicondylitis in a meat-processing factory. Scand $\mathrm{J}$ Work Environ Health 1991;17(1):32-7.

9. Viikari-Juntura E, Kurppa K, Kuosma E, Huuskonen M, Kuorinka I, Ketola R, et al. Prevalence of epicondylitis and elbow pain in the meat-processing industry. Scand J Work Environ Health 1991;17(1):38-45.

10. Ritz BR. Humeral epicondylitis among gas- and waterworks employees. Scand J Work Environ Health 1995;21(6):47886.

11. Ono $Y$, Nakamura $R$, Shimaoka M, Hiruta S, Hattori $Y$, Ichihara $\mathrm{G}$, et al. Epicondylitis among cooks in nursery schools. Occup Environ Med 1998;55(3):172-9.

12. Sevier TL, Wilson JK. Treating lateral epicondylitis. Sports Med 1999;28(5):375-80.

13. Assendelft WJJ, Hay EM, Adshead R, Bouter LM. Corticosteroid injections for lateral epicondylitis: a systematic overview. Br J Gen Pract 1996;46:209-16.

14. Nagler W. Tennis elbow. Am Fam Physician 1977;16(1):95102.

15. Pienimäki T, Karinen P, Kemilä T, Koivukangas P, Vanharanta H. Long-term follow-up of conservatively treated chronic tennis elbow patients: a prospective and retrospective analysis. Scand J Rehabil Med 1998;30(3):159-66.

16. Office of National Statistics. Standard Occupational Classification. London: Her Majesty's Stationery Office, 1991.

17. Matthews JN, Altman DG, Campbell MJ, Royston P. Analysis of serial measurements in medical research. BMJ 1990;300:230-5.

18. SPSS Inc. SPSS for windows, rel. 10.0.0. 1999. Chicago: 
SPSS Inc, 1999.

19. Jorgensen U, Winge S. Injuries in badminton. Sports Med 1990;10(1):59-64.

20. Gruchow HW, Pelletier D. An epidemiologic study of tennis elbow. Incidence, recurrence, and effectiveness of prevention strategies. Am J Sports Med 1979;7(4):234-8.

21. Roetert EP, Brody H, Dillman CJ, Groppel JL, Schultheis JM. The biomechanics of tennis elbow: an integrated approach. Clin Sports Med 1995;14(1):47-57.

22. Mens JM, Stoeckart R, Snijders CJ, Verhaar JA, Stam HJ. Tennis elbow, natural course and relationship with physical activities: an inquiry among physicians. J Sports Med Phys
Fitness 1999;39(3):244-8.

23. Marriott IA, Stuchly MA. Health aspects of work with visual display terminals. J Occup Med 1986;28:833-48.

24. Rossignol AM, Morse EP, Summers VM, Pagnotto LD. Video display terminal use and reported health symptoms among Massachusetts clerical workers. J Occup Med 1987;29:112-8.

25. Yu ITS, Wong TW. Muskuloskeletal problems among VDU workers in a Hong Kong bank. Occup Med 1996;46(4):27580.

Received for publication: 6 August 2001 